\title{
Adherence decision making in the everyday lives of emerging adults with type I diabetes
}

\author{
This article was published in the following Dove Press journal: \\ Patient Preference and Adherence \\ 26 July 2013 \\ Number of times this article has been viewed
}

\author{
Elizabeth A Pyatak' \\ Daniella Florindez' \\ Marc J Weigensberg² \\ 'Division of Occupational Science and \\ Occupational Therapy, University \\ of Southern California, ${ }^{2}$ Department \\ of Pediatrics, Keck School of Medicine, \\ University of Southern California, \\ Los Angeles, CA, USA
}

Purpose: The purpose of this study was to explore motivations underlying nonadherent treatment decisions made by young adults with type 1 diabetes.

Methods: Eight emerging adults each completed a series of semi-structured interviews concerning their approaches to diabetes care, relationships with clinicians, and everyday activities and routines. A narrative thematic analysis was used to develop initial themes and refine them through continued data collection and review of the research literature.

Results: Five themes were identified as motivating nonadherence: (1) efforts to mislead health care providers, (2) adherence to alternative standards, (3) treatment fatigue and burnout, (4) social support problems, and (5) emotional and self-efficacy problems.

Conclusion: Instances of nonadherence generally involved a combination of the five identified themes. Participants reporting nonadherence also described difficulties communicating with care providers regarding their treatment. Nonjudgmental communication between providers and emerging adults may be particularly important in promoting positive health outcomes in this population.

Keywords: compliance, health behavior, nonadherence, motivations

\section{Introduction}

Adherence to treatment recommendations has been a vexing issue in chronic disease management for decades, ${ }^{1}$ as nonadherence to recommended treatments is estimated at $25 \%-50 \%$ across all chronic conditions. ${ }^{1,2}$ A meta-analysis of 50 years of adherence research found that diabetes had the second-lowest adherence rate of 17 chronic conditions, at $67.5 \% .^{2}$ Among young people with type 1 diabetes (T1DM), a study of adherence to insulin treatment found that $28 \%$ of patients obtained less insulin than their prescribed dose, and that lower adherence was associated with more hospital admissions for acute diabetes complications $(P=0.008)$ and diabetic ketoacidosis $(P<0.001) .{ }^{3}$ Systematic reviews of diabetes adherence in both children and adults have demonstrated that increased adherence to prescribed treatments is associated with improved glycemic control ${ }^{4,5}$ and fewer hospitalizations. ${ }^{4}$ Numerous studies have been undertaken seeking to elucidate factors contributing to nonadherence, such as executive function, ${ }^{6}$ family support, ${ }^{7-9}$ social or peer pressure, ${ }^{7,10}$ hypoglycemia unawareness, ${ }^{11}$ depression, ${ }^{12}$ and alcohol consumption. ${ }^{13}$ However, no single factor has been shown to consistently account for the variance in adherence to recommended diabetes care. ${ }^{14}$

The vast majority of research on nonadherence has investigated variables of interest to researchers and care providers, as opposed to first-person perspectives on adherence from people with diabetes themselves. ${ }^{15}$ Those studies which have investigated patients' 
perspectives have highlighted the contrasting views on adherence between patients and providers: providers typically view adherence in the context of pursuing optimal glycemic control and health outcomes, whereas patients seek to balance treatment adherence with other aspects of everyday living, in pursuing optimal quality of life. ${ }^{16,17}$ As such, adherence is an ongoing series of decisions in which patients balance diabetes care with other concerns related to their physical, social, psychological, cultural, and economic life circumstances. ${ }^{17,18}$ Given this perspective, the extent to which nonadherence to prescribed treatments represents negligence, versus reasonable decision making in the context of complex and continually unfolding life circumstances, is not well understood. ${ }^{15}$

The paradigm shift from authoritarian to patient-centered care, exemplified by the chronic care model ${ }^{19}$ and patient empowerment approach ${ }^{20,21}$ is built upon the premise that equitable collaboration between patients and providers will produce improved outcomes in chronic disease management. However, for this approach to be optimally effective, health care providers must develop an understanding of patients' perspectives on what constitutes successful diabetes care, and how everyday life circumstances may facilitate or inhibit their success. Research on patients' perceptions indicates that many feel that their health care providers do not appreciate the daily frustrations, challenges, and trade-offs inherent to managing diabetes. ${ }^{14,16,22}$ Conversely, research on providers' perspectives shows that providers feel frustrated or helpless when patients identify barriers to adherence that they interpret as excuses, or as deep-rooted beliefs that the provider is powerless to change. . $^{23,24}$

The developmental trajectory of young adults has shifted over the past half-century, with the transitional age of approximately 18-25 years now often termed "emerging adulthood." ${ }^{25}$ Comparatively little research has been conducted on the particular needs of, and effective treatment strategies for, emerging adults with diabetes. ${ }^{26,27}$ They are at substantial risk for negative health outcomes, having a three- to sixfold increase in mortality over their nondiabetic peers. ${ }^{26,28}$ Longitudinal studies among this population have revealed that approximately one-third experience significant psychological distress or psychiatric disorders ${ }^{29,30}$ such as depression, eating disorders, self-harm or attempted suicide, and diabetes-related distress, and that $25 \%$ of men and $38 \%$ of women with diabetes develop serious complications in this age period. ${ }^{31}$ Within the limited literature describing patients' perspectives on adherence to diabetes care, no research, of which the authors are aware, has specifically targeted the developmental stage of emerging adulthood.

Given the dearth of knowledge on the perspectives of emerging adults with diabetes regarding adherence, and the research documenting their risk for poor health outcomes, understanding emerging adults' views regarding adherence may provide clinicians with insights that would enable them to form more effective partnerships with emerging adult patients. This may, in turn, facilitate patients and clinicians collaboratively developing more sustainable diabetes care strategies, thereby improving health and quality of life in this population. This article reports on an exploratory qualitative study that aimed, in part, to investigate emerging adults' perspectives on nonadherence to diabetes care. The findings suggest possible directions for future research and potential implications for clinical practice with this population.

\section{Research design and methods Participants}

Eight young adults with T1DM participated in the study. Basic demographic information is described in Table 1. Participants were recruited through a support group for young adults held at a pediatric endocrinology clinic $(n=2)$, advertisements placed in local college newspapers $(n=5)$, and advertisements in a free weekly newspaper $(n=1)$ distributed throughout the greater metropolitan area of Los Angeles. All participants were enrolled in some form of higher education

Table I Basic demographic information

\begin{tabular}{|c|c|c|c|c|c|c|}
\hline Pseudonym & Age, y & Age at dx, y & SES* & Race/Ethnicity & Health insurance & Treatment approach \\
\hline Mark & 25 & 14 & Middle & White & Yes; private & MDI \\
\hline Sadie & 21 & 6 & Middle & White & Yes; private & MDI \\
\hline Leslie & 20 & 15 & High & White & Yes; private & Insulin pump and CGM \\
\hline James & 19 & 7 & Middle & White/Asian & Yes; private & Insulin pump \\
\hline Annabel & 19 & II & Low & Hispanic & Yes; public & MDI \\
\hline Jenny & 21 & 4 & Low & Hispanic & No & MDI \\
\hline Sergio & 23 & 1 & High & White & Yes; private & MDI \\
\hline Nina & 20 & 12 & High & White & Yes; private & Insulin pump \\
\hline
\end{tabular}

Note: *Defined by parents' income and highest level of educational attainment.

Abbreviations: CGM, continuous glucose monitor; dx, diagnosis; MDI, multiple daily injections; SES, socioeconomic status. 
(ranging from community college to graduate school). Four had part-time jobs, two had worked part or full time prior to study enrollment but were no longer working, and two had never worked outside the home. Two participants lived with their parents at the time of study participation, and six lived independently (alone, with roommates, or with a significant other).

Inclusion criteria in the study were: $18-25$ years of age at time of study enrollment, having been diagnosed with T1DM for at least 1 year, and residence within a 50-mile radius of downtown Los Angeles. The presence of comorbid physical or mental health disorders that currently affect participation in activities of daily living was used as an exclusion criterion. In addition to the eight participants who enrolled in the study, four additional prospective participants inquired about the study but did not meet the inclusion criteria due to having a diagnosis of prediabetes $(n=2)$ or a family history of diabetes with no current diagnosis $(n=2)$. One prospective participant attended the support group for young adults with diabetes described but declined to participate. Study procedures were approved by the Institutional Review Board at the authors' institution. Participants received written and verbal information about the study and completed an informed consent form prior to their enrollment.

\section{Data collection}

Each participant completed a series of six semi-structured interviews averaging 45-60 minutes in length; all interviews were conducted by the first author, audio recorded with a digital voice recorder, and transcribed verbatim for analysis. Interviews took place approximately biweekly in a location of the participant's choosing, typically their home or college campus. A US\$75 stipend was provided to each participant on completion of the series of interviews. The interviews were aimed at developing a comprehensive understanding of participants' everyday lives and the role of diabetes management in their daily routines (see "Interview guide" in the "Supplementary material" section). Participants were asked about their past and current approaches to diabetes management, challenges and dilemmas related to diabetes care, interactions with clinicians, everyday habits and routines, physical and social environments, and other factors determined in the course of interviews to be influential to diabetes care in the context of each participant's individual life circumstances, such as their decision to use or not use an insulin pump, and how parents and friends supported or hindered their diabetes management.

\section{Data analysis}

A narrative thematic approach guided data analysis, as outlined by Riessman. ${ }^{32}$ This approach aims to discern common themes across cases, while preserving the participants' own words as the unit of analysis rather than reducing them to codes. Themes were developed through an iterative process in which a priori theories (eg, emerging adulthood) helped guide the initial identification of themes; these themes were then refined or disconfirmed as new data were collected and pertinent theoretical concepts were extracted from the research literature. The first author developed initial themes, analyzing them theoretically by reviewing existing research for relevant concepts, and inductively by searching for supporting or disconfirming interview data.

Through this process, themes were refined until they represented a synthesis of the data across individual cases. A major theme that emerged from the data related to participants' adherence to agreed-on diabetes treatments. Within this theme, five supporting concepts were identified that described participants' processes and motivations for making nonadherent decisions about their diabetes care. The findings were reviewed by two content experts in occupational therapy and endocrinology to assess the plausibility of the identified themes and concepts. The construct of "selfefficacy," embedded within a theme of "emotional problems," was deconstructed as a cognitive rather than an emotional construct. Therefore, this finding was delineated separately in the final analysis. Additionally, the content experts cautioned that participants' reports of what happened in medical appointments were the patient's perceptions, and the medical providers may have a different interpretation; therefore, care was taken in reporting these findings as such.

\section{Results}

Of the eight study participants, three did not report significant difficulty adhering to diabetes management treatment recommendations from their health care providers. Some key factors which appeared to facilitate their adherence included having health care providers who adopted a collaborative rather than authoritarian approach to care, family members and friends who were supportive but not overbearing, and participants' satisfaction with their current treatment approach.

The five remaining participants reported consistently making nonadherent decisions about their diabetes management. Among those participants, the following factors were found to influence their nonadherence: efforts to mislead health care providers, adherence to alternative standards, treatment fatigue and burnout, social support problems, and 
emotional and self-efficacy problems. Detailed explanations of each factor, with representative quotes from participant interviews, are presented following. Quotes and other data are identified by pseudonyms to protect the identities of study participants.

Participants reported a diverse range of experiences with health care providers. Table 2 outlines the number of care providers each participant had had since being diagnosed with T1DM, and reasons cited for changing

Table 2 Changes in health care providers (HCPs)

\begin{tabular}{|c|c|c|c|}
\hline Pseudonym & $\begin{array}{l}\text { Duration of } \\
\text { diabetes }\end{array}$ & $\begin{array}{l}\text { Number } \\
\text { of HCP } \\
\text { changes* }\end{array}$ & $\begin{array}{l}\text { Reason cited for } \\
\text { changing HCP*** }\end{array}$ \\
\hline Sergio & 22 & 8 & $\begin{array}{l}\text { - Moved }(n=1) \\
\text { - Dissatisfied with care } \\
(n=6) \\
\text { - Transition from } \\
\text { pediatric to adult } \\
\text { care }(n=1)\end{array}$ \\
\hline Jenny & 17 & 0 & $\begin{array}{l}\text { n/a; same HCP since } \\
\text { diagnosis }\end{array}$ \\
\hline Sadie & 15 & 2 & $\begin{array}{l}\text { - Transition from pediatric } \\
\text { to adult care }(n=I) \\
\text { - Dissatisfied with care } \\
(n=I)\end{array}$ \\
\hline James & 12 & 0 & $\begin{array}{l}\mathrm{n} / \mathrm{a} \text {; same HCP since } \\
\text { diagnosis }\end{array}$ \\
\hline Mark & 9 & 3 & $\begin{array}{l}\text { - Moved }(n=2) \\
\text { - Changed health } \\
\text { insurance }(n=1)\end{array}$ \\
\hline Annabel & 8 & 3 & $\begin{array}{l}\text { - Dissatisfied with care } \\
(n=2) \\
\text { - Reason unknown }(n=1)\end{array}$ \\
\hline Nina & 8 & 4 & $\begin{array}{l}\text { - Moved }(n=1) \\
\text { - Dissatisfied with care } \\
(n=3)\end{array}$ \\
\hline Leslie & 5 & 2 & $\begin{array}{l}\text { Dissatisfied with care } \\
(n=2)\end{array}$ \\
\hline $\begin{array}{l}\text { Total } \\
(\text { mean } \pm S D)\end{array}$ & $12.0 \pm 5.3$ & $2.8 \pm 2.4$ & $\begin{array}{l}\text { - Dissatisfied with care } \\
(n=14) \\
\text { - Moved }(n=4) \\
\text { - Transition from pediatric } \\
\text { to adult care }(n=2) \\
\text { - Changed health } \\
\text { insurance }(n=1) \\
\text { - Reason unknown }(n=1)\end{array}$ \\
\hline
\end{tabular}

Notes: *Number includes only HCPs identified specifically (by name or location) in interview transcripts. We excluded HCPs identified only through general statements such as the following: "There aren't many diabetes doctors ... that l've actually left out. Let's say there's I. 5 million people in the city and maybe 20, 30 doctors. Maybe I've seen, like, 15 of them" (Sergio). **Dissatisfied with care encompasses: perception of threats, judgment, or blame regarding activity choices; perceived discrimination or differential treatment on the basis of personal or family characteristics; HCP's unwillingness to adapt treatment regimen to address participant's lifestyle concerns; or participant feeling compelled to lie to HCP to avoid any of the listed issues. These are presented in aggregate because participants typically identified two or more factors as contributing to their dissatisfaction with a given HCP.

Abbreviation: SD, standard deviation. providers. Two participants had seen the same provider since being diagnosed. The remaining six participants had seen a variety of health care providers, in multiple settings, since diagnosis. Owing to the high geographic mobility of emerging adults, although all participants were living in Los Angeles at the time of their study participation, they had received diabetes care (excluding urgent care during travel) in eight metropolitan areas spanning five US states and two countries.

\section{Efforts to mislead health care providers}

Through their experiences in navigating medical systems, participants developed shrewd strategies for managing interactions with clinicians, many of which could be classified as nonadherent. For example, to manage the information seen by clinicians, prior to medical appointments, participants reported testing more often than usual, or not testing when they suspected their blood sugar was above or below the optimal range. This strategy was sometimes part of a larger effort to steer the medical appointment toward addressing a specific concern of the participant. In these instances, they sought to avoid presenting information (such as an anomalous high blood sugar) that they feared the clinician would want to discuss in detail, derailing their efforts to discuss a different issue in their limited appointment time. As Matthew explained: "Say [a high blood sugar] happened the week before I was going in ... They would think, well, if he doesn't see this as a problem, then we have to talk about it, and it changes the conversation."

In addition to withholding information, participants reported lying to health care providers when they felt that being honest would lead to a confrontation. In many cases, participants related that their nonadherence was due to conflicting demands in their everyday routines, rather than a lack of knowledge about how to manage their diabetes. Sadie stated, "It's kind of insulting when you're hearing that you should check 30 minutes before you eat. I know. But I'm doing something else at that time and I choose not to. It's not that I didn't know." Some participants reported that their health care providers, in response to disclosures of nonadherence, responded with authoritarian lecturing about the consequences of their actions. A common motivation for lying was related to alcohol use. Some participants reported that clinicians' reactions to their admissions of alcohol use or other risky activities were met with scare tactics or stock responses (eg, a recommendation to have one glass of wine with dinner) that were not relevant to their lifestyles. For example, Leslie shared: 
[They say] don't drink and don't do drugs and don't stay up late, and I'm like, did you go to college? Because, obviously not. Everyone's going to do these things. You need to say yes, you shouldn't drink - but if you do, then A, B, C, and D.

When participants perceived their health care providers as being unresponsive to the realities of their daily lives, they avoided discussing alcohol use during appointments. However, they reported that they continued to drink, and were interested in learning more about how it affected their blood sugar.

\section{Adhering to alternative standards}

Finding their treatment regimens onerous, or being unable to attain the desired glycated hemoglobin (A1C) and blood glucose targets, led some participants to abandon their health care providers' treatment recommendations. Some participants actively avoided learning about new recommendations for managing diabetes, because they viewed this information as potentially increasing their treatment burden. As Annabel expressed, "I want to learn more about [diabetes care], but in a way I'm kind of scared to learn more because I'm going to realize how much more I'm going to have to do to take care of myself." Others developed strategies that enabled them, per their self-report, to maintain good control of diabetes although they diverged from recommendations on how to do so. For instance, one participant who feared hypoglycemia took insulin midway through or at the end of a meal, rather than before eating as was recommended. Despite this, he reported that his glycated hemoglobin (A1C) was consistently below 7 , and he therefore had little motivation to conform to the recommended timing of his insulin dose.

Finally, some participants were aggravated by changes in their treatment over time, as practitioners adopted recommendations for intensive control following the Diabetes Control and Complications Trial/Epidemiology of Diabetes Interventions and Complications trial, ${ }^{33,34}$ and as they matured into adulthood, when blood glucose goals are more stringent than for children and adolescents. ${ }^{35}$ Some participants chose to reject new treatment recommendations, and evaluate their diabetes management success based on the standards they had previously been given. As Matthew articulated:

When I was diagnosed at age 14, I was in pretty good control by whatever standards they were using at the time ... That sort of stuck in my head, and I have this impression of myself as having really good control. But more and more they have better standards.
This approach enabled participants to maintain the selfconcept of being a "good diabetic" despite not attaining optimal levels of control.

\section{Treatment fatigue and burnout}

Participants who experienced fatigue or burnout grew weary of performing self-care tasks, visiting health care providers, and taking required medications, expressing that while each of these discrete actions was manageable in itself, the cumulative effort of attending to these tasks every day, with no end in sight, became overwhelming over time. Sadie shared, "When you try to do everything by the books, sometimes there's a tendency to feel like it's not practical. How can you keep that going forever? Because I'm not going to get better.' The tendency to burn out was particularly true for those who had developed complications of diabetes or who had comparatively intensive treatment regimens. One participant described adopting a mindset she called "going on vacation," which entailed devoting as little effort to diabetes management as possible without inducing acute complications. As participants burned out, they lowered their standards with regard to how closely they adhered to treatment recommendations. Participants emphasized, however, that they viewed these phases as part of a normal cycle of ebbs and flows of effort, rather than a long-term or permanent state. As John said:

I was just so sick of testing my blood, 'cause I just didn't want to do it anymore. So I didn't do as many tests, and then my doctor, she's like, you need to do more than two or three a day, and so - I started doing more, recently.

Another factor contributing to treatment fatigue was the feeling of chasing a moving target. Those who had had T1DM for many years had experienced tightening standards as the benefits of intensive treatment were demonstrated, advances in technology made better control possible, and treatment guidelines grew more stringent. Some expressed frustration that these advancements had resulted in unrealistic expectations. These shifting standards left some feeling continually behind the curve in their efforts to adhere to treatment guidelines, even as their clinical indicators remained the same. As Annabel said, "When I get to the finish point [of good control], it's not really the finish point, because it's not like I can stop once I pass it ... It would be another thing for me to just keep going after."

\section{Social support problems}

Participants positioned within supportive social networks were less likely to report having difficulty with adherence than those 
who were not. Participants identified supportive friends and family members as being people who maintained an interest in participants' health without being overbearing, allowing them to manage their care independently but remaining available to assist if needed. For example, Sergio said of his family's support that, "It helped me out a lot because I saw that they cared, but I also saw that they didn't bug me, which is very important."

Some participants struggled to exert their autonomy as they entered adulthood. One participant, John, exemplified the challenge of having an overbearing family member, which made it difficult for him to develop independence with respect to diabetes care. Although he was 19 years old and a sophomore in college, his mother still sat in the exam room with him for the entirety of each medical appointment. He was reluctant to ask her to leave out of concern that he would upset her, and reported that his care providers had not addressed the issue either. His mother also carefully monitored his diabetes care at home:

My mom tells me when dinner is going to be ready, so I can bolus. Sometimes I do, but usually I don't. If I do it in the middle of the meal, she says, "What did Dr Hunter tell you? You have to do it before, why are you doing it now?" [If] I say I just forgot, she says, "You should remember next time!"

This situation resulted in John resorting to deception when making decisions about his care that departed from his prescribed treatment regimen, without any feedback on the appropriateness of his decisions, or assistance in adapting his treatment regimen to address his concerns (in this case, a fear of hypoglycemia).

By contrast, other participants with poor social support felt neglected by their family and friends. One such participant, Annabel, reported that she had been expected to manage her diabetes independently since being diagnosed as a preadolescent, a situation which had contributed to multiple hospitalizations and placement in foster care at one point. Her reaction to her family's disinterest in her health was to act out with nonadherent behaviors, hoping this would attract their care and attention:

I'll tell my mom that I'm not checking my blood sugar and she says, "That's not good." But that's all she says, she doesn't say “Oh, why don't you check it now?” ... It's like I'll just wait for somebody to tell me. I think it's just something that I haven't had, and I want to have just once.

After so long, just once, I would be happy.

Annabel realized she was putting her health at risk, but her desire to garner support from her family was greater than her fear of the negative consequences. Because her nonadherent behavior was deeply rooted in this family dynamic, it was unlikely to change significantly without addressing these underlying issues.

\section{Emotional and self-efficacy problems}

Emotional states significantly influenced adherence for several participants. A major driver of nonadherent behavior was anxiety, which led to denial and avoidance. An already discussed example was John, who delayed taking insulin at mealtimes because of a fear of hypoglycemia. While he reported maintaining good control despite this divergence from treatment recommendations, for others avoidance posed more of a health risk. One participant, Annabel, reported rarely checking her blood sugar. A significant factor motivating this behavior was her fear that the number would be too high. She, and other participants, also expressed being in denial about the consequences of high blood sugar; as one said, "I know what will happen ... [But] for some reason, it doesn't hit me. It's like I know it, but I won't accept that it's going to happen."

Embarrassment was another emotional factor contributing to nonadherence. Several participants recalled being singled out for negative attention by their peers or by those in positions of authority. This deterred them from performing self-management tasks in the presence of others. As Leslie shared, "We'll be out to dinner and I'll check [my blood sugar] under the table, and you can tell the conversation has stopped because everyone is staring. And I'm like, 'What are you doing? This is weird." Participants were also embarrassed by receiving positive attention in the presence of their peers; for example, being praised for their diligence in their diabetes care. As Matthew said, "I hate being an example to people, because I didn't feel like I was doing anything all that impressive. I didn't have anything inspiring to say." Particularly in emerging adulthood, when fitting in with peers is a high priority, embarrassment was a significant driver of nonadherent behavior.

Some participants lacked self-efficacy, or belief in their capability to accomplish certain goals, with respect to diabetes care. A lack of self-efficacy tended to de-motivate participants to adhere to treatment recommendations, because they felt they would be likely to fail despite their best efforts. Leslie shared her feelings thus: "There's always so much more I could do. It just seems like that's too daunting ... I don't know if I'll ever feel good enough, as far as being in control." Low diabetes-related self-efficacy occurred both among those with comparatively more and less intensive 
treatment regimens. Complex psychosocial issues, such as Annabel's perception of family neglect (as described earlier), played a significant role in influencing participants' self-efficacy and, indirectly, their adherence to treatment recommendations. Annabel was quite clear in expressing these feelings of failure:

I'm failing. I'm not even near the finish point. The starting line is right here, and I'm not getting far ... I want to get there so bad, it's just I don't know how to go about it ... There are days when I wake up and think, God, I feel like such a failure.

\section{Discussion}

The factors identified by this study provide preliminary insight into the reasons emerging adults with T1DM offer for their nonadherent behavior. These instances of nonadherence were typically motivated by a combination of personal factors, including developmental and psychosocial issues and contextual factors, including participants' social networks and health care systems within which they received care. For example, the developmentally appropriate tendency of emerging adults to take risks in their alcohol use sometimes led their health care providers to express concern via (what participants perceived as) lecturing or scare tactics, which in turn led participants to withhold information about alcohol use in future health care encounters.

As previously discussed, a combination of factors was at play in motivating many nonadherent treatment decisions. For instance, Annabel, in addition to coping with family circumstances that led her to seek attention through nonadherence, also lacked the self-efficacy to believe that she could make significant changes to her behavior, and was reluctant to learn more about diabetes treatment recommendations for fear of falling even further short of expectations for managing her illness. Therefore, when addressing nonadherence in clinical settings, it is important to probe for multiple interrelated factors that may underlie patients' motivations to deviate from treatment recommendations.

A crucial finding is the importance of open communication concerning patients' actual diabetes management practices so health care providers can provide relevant treatment recommendations. Previous research has advocated for the use of a collaborative model of care in this population as opposed to the traditional authoritarian model, ${ }^{27}$ but per the reports of the participants in this study, many health care providers have not yet adopted this approach. As reported elsewhere, ${ }^{19}$ this study found that emerging adults with diabetes are nonadherent not due to capriciousness or disregard for their health, but rather as an attempt to balance competing priorities within their daily lives. When patients and clinicians can have an honest dialogue about the circumstances surrounding nonadherence, they are more likely to arrive at a mutual agreement about how best to tailor treatment to be responsive to the patient's concerns, priorities, and life circumstances, enhancing the likelihood of adherence in the future.

This study validates previous research documenting the influence of several factors, including social support problems, ${ }^{8,19,36}$ self-efficacy, ${ }^{37,38}$ treatment fatigue and burnout, ${ }^{8,39}$ and embarrassment resulting from the perception of negative reactions of peers ${ }^{8,11,19}$ on nonadherence. However, this literature has largely focused on adolescents ${ }^{8,10,18,36,39}$ or adults over 30 years of age; ${ }^{37,38}$ therefore, this study contributes evidence that such findings are also applicable in an emerging adult population. Further research is needed to clarify the similarities and differences in how these issues manifest at different ages. In research examining adherence among emerging adults with different chronic conditions, similar constructs have been identified, including depression and poor family support in emerging adults with cancer, ${ }^{40}$ and social barriers to adherence in youth with HIV. ${ }^{41}$ Research examining emerging adult adherence across chronic conditions may be fruitful, to determine which issues are likely to affect emerging adults in general and which may be particular to certain conditions.

In addition to validating existing findings, this study contributes information on themes not widely reported on in the medical literature. Although studies have documented patients changing their diabetes self-management practices before a medical appointment in order to improve their numbers, ${ }^{42,43}$ this study provides possible evidence of a different motivation for patients employing such behaviors - for instance, eliminating extraneous data to prevent distraction from other issues the patient wishes to discuss during a medical appointment. This finding prompts questions about the motivations for this practice in typical clinical settings. Similarly, the finding that some patients refuse to evaluate themselves according to current guidelines for the management of diabetes, preferring to assess their health status according to their own individualized standards, has not been reported in the existing medical literature. Further research on the prevalence, motivations for, and implications of such practices among patients is warranted.

A significant limitation of this study was the lack of method triangulation, such as chart review or interviews with health care 
providers, to validate participants' self-reported adherence and clinical health indicators. This decision was made to maximize the validity of the interview data. A concern was that seeking permission to contact participants' health care providers would compromise the interviewer's ability to collect data on potentially sensitive topics such as illicit drug and alcohol use, due to participants' perceptions that such information could be disclosed to their health care providers. However, interviewing health care providers may have provided alternative explanations for some of the unhelpful interactions participants reported experiencing during medical appointments.

An additional limitation, inherent to qualitative research, is the small sample size, which limits generalizability. Therefore, researchers and clinicians should exercise careful judgment in determining whether these findings are applicable to the populations with whom they work. Because this study does not provide data on the incidence of the reported behaviors among the targeted population, a possible next step would be to develop a quantitative measure of the factors contributing to nonadherence found in this and other studies, to be administered to a large sample of emerging adults. Such research would contribute information on the prevalence and severity of these issues, providing guidance as to what may be most urgent to address in future research and clinical practice.

\section{Conclusion}

This study offers preliminary information regarding motivations for nonadherence on the part of emerging adults with T1DM. These decisions are often attempts to reconcile competing demands within the individual's everyday life circumstances. Contributing to participants' nonadherent behaviors were personal factors such as embarrassment, low self-efficacy, and diabetes burnout, as well as contextual factors such as poor social support and poor communication with health care providers. These factors were often interrelated, suggesting that a multifactorial approach to resolving nonadherence is warranted if such behavior is identified as adversely affecting the individual's health.

\section{Acknowledgments}

The authors thank Drs Florence Clark, Mary Lawlor, Ann Neville-Jan, and Mike Carlson of the University of Southern California Division of Occupational Science and Occupational Therapy for their feedback on previous drafts of this manuscript. This paper was written in partial fulfillment of the requirements for the Doctor of Philosophy degree in Occupational Science at the University of Southern California.

\section{Disclosure}

The authors disclose receipt of the following financial support for the research, authorship, and/or publication of this article. The research was supported in part by a dissertation research grant from the American Occupational Therapy Foundation. Dr Pyatak is a KL2 Scholar awarded under the KL2 Mentoring Research Career Development Award through Southern California Clinical and Translational Science Institute at University of Southern California, Keck School of Medicine (NCRR/NCATS \#KL2RR031991; PI: T Buchanan).

The authors declare no other potential conflicts of interest with respect to the research, authorship, and/or publication of this article.

\section{References}

1. Vermeire E, Hearnshaw H, Van Royen P, Denekens J. Patient adherence to treatment: three decades of research. A comprehensive review. J Clin Pharm Ther. 2001;26(5):331-342.

2. DiMatteo MR. Variations in patients' adherence to medical recommendations: a quantitative review of 50 years of research. Med Care. 2004;42(3):200-209.

3. Morris AD, Boyle DI, McMahon AD, Greene SA, MacDonald TM, Newton RW. Adherence to insulin treatment, glycaemic control, and ketoacidosis in insulin-dependent diabetes mellitus. The DARTS/MEMO Collaboration. Diabetes Audit and Research in Tayside Scotland. Medicines Monitoring Unit. Lancet. 1997;350(9090):1505-1510.

4. Asche C, LaFleur J, Conner C. A review of diabetes treatment adherence and the association with clinical and economic outcomes. Clin Ther. 2011;33(1):74-109.

5. Hood KK, Peterson CM, Rohan JM, Drotar D. Association between adherence and glycemic control in pediatric type 1 diabetes: a metaanalysis. Pediatrics. 2009;124(6):e1171-e1179.

6. McNally K, Rohan J, Pendley JS, Delamater A, Drotar D. Executive functioning, treatment adherence, and glycemic control in children with type 1 diabetes. Diabetes Care. 2010;33(6):1159-1162.

7. Borus JS, Laffel L. Adherence challenges in the management of type 1 diabetes in adolescents: prevention and intervention. Curr Opin Pediatr. 2010;22(4):405-411.

8. Pereira MG, Berg-Cross L, Almeida P, Machado JC. Impact of family environment and support on adherence, metabolic control, and quality of life in adolescents with diabetes. Int J Behav Med. 2008;15(3): 187-193.

9. Hsin O, La Greca AM, Valenzuela J, Moine CT, Delamater A. Adherence and glycemic control among Hispanic youth with type 1 diabetes: role of family involvement and acculturation. $J$ Pediatr Psychol. 2010;35(2):156-166.

10. Hains AA, Berlin KS, Davies WH, Parton EA, Alemzadeh R. Attributions of adolescents with type 1 diabetes in social situations: relationship with expected adherence, diabetes stress, and metabolic control. Diabetes Care. 2006;29(4):818-822.

11. Smith CB, Choudhary P, Pernet A, Hopkins D, Amiel SA. Hypoglycemia unawareness is associated with reduced adherence to therapeutic decisions in patients with type 1 diabetes: evidence from a clinical audit. Diabetes Care. 2009;32(7):1196-1198.

12. Katon W, Russo J, Lin EH, et al. Diabetes and poor disease control: is comorbid depression associated with poor medication adherence or lack of treatment intensification? Psychosom Med. 2009;71(9): 965-972.

13. Ahmed AT, Karter AJ, Liu J. Alcohol consumption is inversely associated with adherence to diabetes self-care behaviours. Diabet Med. 2006;23(7):795-802. 
14. Vermeire E, Hearnshaw H, Rätsep A, et al. Obstacles to adherence in living with type-2 diabetes: an international qualitative study using meta-ethnography (EUROBSTACLE). Prim Care Diabetes. 2007;1(1): 25-33.

15. Anderson RM, Funnell MM. Compliance and adherence are dysfunctional concepts in diabetes care. Diabetes Educ. 2000;26(4):597-604.

16. Anderson RM, Funnell MM. Patient empowerment: myths and misconceptions. Patient Educ Couns. 2010;79(3):277-282.

17. Vermeire E, Van Royen P, Coenen S, Wens J, Denekens J. The adherence of type 2 diabetes patients to their therapeutic regimens: a qualitative study from the patient's perspective. Practical Diabetes International. 2003;20(6):209-214.

18. Hortensius J, Kars MC, Wierenga WS, Kleefstra N, Bilo HJ, van der Bijl JJ. Perspectives of patients with type 1 or insulin-treated type 2 diabetes on self-monitoring of blood glucose: a qualitative study. $B M C$ Public Health. 2012;12:167.

19. Hunt LM, Arar NH. An analytical framework for contrasting patient and provider views of the process of chronic disease management. Med Anthropol Q. 2001;15(3):347-367.

20. Davidson M, Penney ED, Muller B, Grey M. Stressors and self-care challenges faced by adolescents living with type 1 diabetes. Appl Nurs Res. 2004;17(2):72-80.

21. Wagner EH, Austin BT, VonKorff M. Organizing care for patients with chronic illness. Milbank Q. 1996;74(4):511-544.

22. Matthews SM, Peden AR, Rowles GD. Patient-provider communication: understanding diabetes management among adult females. Patient Educ Couns. 2009;76(1):31-37.

23. Hunt LM, Arar NH, Larme AC. Contrasting patient and practitioner perspectives in type 2 diabetes management. West J Nurs Res. 1998;20(6): 656-676; discussion 677-682.

24. Wens J, Vermeire E, Royen PV, Sabbe B, Denekens J. GPs' perspectives of type 2 diabetes patients' adherence to treatment: a qualitative analysis of barriers and solutions. BMC Fam Pract. 2005;6(1):20.

25. Arnett JJ. Emerging adulthood. A theory of development from the late teens through the twenties. Am Psychol. 2000;55(5):469-480.

26. Anderson BJ, Wolpert HA. A developmental perspective on the challenges of diabetes education and care during the young adult period. Patient Educ Couns. 2004;53(3):347-352.

27. Peters A, Laffel L; American Diabetes Association Transitions Working Group. Diabetes care for emerging adults: recommendations for transition from pediatric to adult diabetes care systems: a position statement of the American Diabetes Association, with representation by the American College of Osteopathic Family Physicians, the American Academy of Pediatrics, the American Association of Clinical Endocrinologists, the American Osteopathic Association, the Centers for Disease Control and Prevention, Children with Diabetes, The Endocrine Society, the International Society for Pediatric and Adolescent Diabetes, Juvenile Diabetes Research Foundation International, the National Diabetes Education Program, and the Pediatric Endocrine Society (formerly Lawson Wilkins Pediatric Endocrine Society). Diabetes Care. 2011;34(11):2477-2485.

28. Wibell L, Nyström L, Ostman J, et al. Increased mortality in diabetes during the first 10 years of the disease. A population-based study (DISS) in Swedish adults 15-34 years old at diagnosis. J Intern Med. 2001;249(3):263-270.
29. Bryden KS, Dunger DB, Mayou RA, Peveler RC, Neil HA. Poor prognosis of young adults with type 1 diabetes: a longitudinal study. Diabetes Care. 2003;26(4):1052-1057.

30. Hislop AL, Fegan PG, Schlaeppi MJ, Duck M, Yeap BB. Prevalence and associations of psychological distress in young adults with type 1 diabetes. Diabet Med. 2008;25(1):91-96.

31. Bryden KS, Peveler RC, Stein A, Neil A, Mayou RA, Dunger DB. Clinical and psychological course of diabetes from adolescence to young adulthood: a longitudinal cohort study. Diabetes Care. 2001;24(9): $1536-1540$.

32. Riessman CK. Narrative Methods for the Human Sciences. Thousand Oaks, CA: Sage; 2008.

33. Diabetes Control and Complications Trial/Epidemiology of Diabetes Interventions and Complications (DCCT/EDIC) Research Group, Nathan DM, Zinman B, et al. Modern-day clinical course of type 1 diabetes mellitus after 30 years' duration: the diabetes control and complications trial/epidemiology of diabetes interventions and complications and Pittsburgh epidemiology of diabetes complications experience (1983-2005). Arch Intern Med. 2005;169(14): 1307-1316.

34. The effect of intensive treatment of diabetes on the development and progression of long-term complications in insulin-dependent diabetes mellitus. The Diabetes Control and Complications Trial Research Group. N Engl J Med. 1993;329(14):977-986.

35. American Diabetes Association. Standards of medical care in diabetes - 2012. Diabetes Care. 2012;(35 Supp1 1):S11-S63.

36. Wysocki T, Greco P. Social support and diabetes management in childhood and adolescence: influence of parents and friends. Curr Diab Rep. 2006;6(2):117-122.

37. Aljasem LI, Peyrot M, Wissow L, Rubin RR. The impact of barriers and self-efficacy on self-care behaviors in type 2 diabetes. Diabetes Educ. 2001;27(3):393-404.

38. Sarkar U, Fisher L, Schillinger D. Is self-efficacy associated with diabetes self-management across race/ethnicity and health literacy? Diabetes Care. 2006;29(4):823-829.

39. Buckloh LM, Lochrie AS, Antal H, et al. Diabetes complications in youth: qualitative analysis of parents' perspectives of family learning and knowledge. Diabetes Care. 2008;31(8):1516-1520.

40. Kondryn HJ, Edmondson CL, Hill J, Eden TO. Treatment non-adherence in teenage and young adult patients with cancer. Lancet Oncol. 2011;12(1):100-108.

41. Rao D, Kekwaletswe TC, Hosek S, Martinez J, Rodriguez F. Stigma and social barriers to medication adherence with urban youth living with HIV. AIDS Care. 2007;19(1):28-33.

42. Ferzacca S. "Actually, I don't feel that bad": managing diabetes and the clinical encounter. Med Anthropol Q. 2000;14(1):28-50.

43. Naemiratch B, Manderson L. Control and adherence: living with diabetes in Bangkok, Thailand. Soc Sci Med. 2006;63(5):1147-1157. 


\section{Supplementary material Interview guide}

1. Diagnosis experience

a. How old were you when you were diagnosed with diabetes?

b. Tell me about when you first found out you had diabetes.

i. What kinds of things were you thinking? Feeling?

c. How did you first learn how to manage the disease?

d. What things are different about your life now compared to before you had diabetes?

2. Ongoing management of the disease

a. What do you do now to take care of your diabetes?

b. Is there anything you do differently now compared to what you did in the past?

c. Tell me how you figured out what works best for you in managing diabetes.

d. What do you find easy about managing diabetes? What do you find difficult?

e. Was there ever a time that you made a mistake in managing your diabetes, or something went wrong that wasn't your fault? What happened?

f. How do you manage ...

i. ongoing medical care/prescriptions?

ii. daily self-care?

iii. finances/health insurance?

iv. special situations (eg, sick days, drinking, travel)?

3. Life as an emerging adult with diabetes

a. What is it like to have diabetes as a young adult?

b. Does having diabetes ever affect the things you do, or would like to do?

c. How do people respond when they learn that you have diabetes?

i. What do they say? Do?

ii. How do their responses affect you?

d. What do you think would be different about your life if you didn't have diabetes?

e. Do you ever think about the future? What do you imagine it being like?

4. Is there anything else that is important for me to know about your experiences?

5. Overall, what is the most significant way that diabetes has affected your life?

\section{Publish your work in this journal}

Patient Preference and Adherence is an international, peer-reviewed, open access journal focusing on the growing importance of patient preference and adherence throughout the therapeutic continuum. Patient satisfaction, acceptability, quality of life, compliance, persistence and their role in developing new therapeutic modalities and compounds to optimize clinical outcomes for existing disease states are major areas of interest. This journal has been accepted for indexing on PubMed Central. The manuscript management system is completely online and includes a very quick and fair peer-review system. Visit http://www.dovepress.com/ testimonials.php to read real quotes from published authors. 